\title{
Article \\ Mechanical Properties and Leak-Tightness of Polymeric Pipe Adhesive Joints
}

\author{
Anna Rudawska ${ }^{1, *(\mathbb{D}}$, Magd Abdel Wahab ${ }^{2}\left(\mathbb{D}\right.$, Miroslav Müller $^{3}(\mathbb{D}$ and Dana Stančeková 4 (D) \\ 1 Faculty of Mechanical Engineering, Lublin University of Technology, Nadbystrzycka 36, \\ 20-618 Lublin, Poland \\ 2 Faculty of Engineering and Architecture, Ghent University, Technologiepark Zwijnaarde 903, \\ B-9052 Zwijnaarde, Belgium; magd.abdelwahab@ugent.be \\ 3 Faculty of Engineering, Czech University of Life Science Prague, 16521 Prague, Czech Republic; \\ muller@tf.czu.cz \\ 4 Department of Machining and Manufacturing Technologies, Faculty of Mechanical Engineering, \\ University of Zilina, Univerzitna 8215/1, 01026 Žilina, Slovakia; dana.stancekova@fstroj.uniza.sk \\ * Correspondence: a.rudawska@pollub.pl; Tel.: +48-81-53-84-232
}

Citation: Rudawska, A.; Wahab, M.A.; Müller, M.

Stančeková, D. Mechanical Properties and Leak-Tightness of Polymeric Pipe Adhesive Joints. Appl. Mech. 2022, 3, 64-77. https://doi.org/10.3390/ applmech3010004

Received: 7 October 2021

Accepted: 30 December 2021

Published: 4 January 2022

Publisher's Note: MDPI stays neutral with regard to jurisdictional claims in published maps and institutional affiliations.

Copyright: (c) 2021 by the authors Licensee MDPI, Basel, Switzerland. This article is an open access article distributed under the terms and conditions of the Creative Commons Attribution (CC BY) license (https:// creativecommons.org/licenses/by/ $4.0 /)$.

\begin{abstract}
This paper presents issues related to the determination of the selected mechanical properties of adhesive joints made of polymeric pipes and the evaluation of the leak-tightness of the adhesive joints. The article attempts to demonstrate that the type of adhesive may affect the quality of adhesive joints in terms of both tightness and strength of joints. Five types of the polymer pipes differing in a polypropylene and a polyvinyl chloride, diameter and a wall thickness were used in the experiments. Two types of the adhesives were used to make the adhesive joints: Loctite $3430 \mathrm{~A} \& \mathrm{~B}$ Hysol, a two-component epoxy adhesive, and Loctite 406, a one-component cyanoacrylate adhesive. Based on the leak-tightness tests results, it was possible to determine the quality of their adhesive joints without damaging the samples, while their tensile strength was determined through the strength tests. The tests performed allowed for the conclusion that the use of the polyvinyl chloride pipes and Loctite 406 one-component adhesive is recommended for this type of adhesive joints.
\end{abstract}

Keywords: mechanical properties; leak-tightness; strength; adhesive joints

\section{Introduction}

The adhesive joints should be characterized by the adequate strength depending on whether they are made with contact, assembly or structural adhesives [1,2]. The strength of the adhesive joints is affected by many factors related to the adhesive itself, the bonding process and the type of the adherends. Any deviation from the adopted steps of this process may result in significant defects of the adhesive joint. Correctly performing the adhesive bonding process allows one to obtain the joint, which meets requirements [3-5].

The bonding technology can also be used when making joints in piping systems [6-8]. The adhesive joints in the case of various plumbing systems (central heating, as well as hot water, i.e., domestic hot water, supply pipes and piping) belong to the nonseparable joints, in which it is not possible to separate without destroying the adherends. The plumbing systems are made of both metallic and polymeric materials [9]. Some publications emphasize the use of the polymeric materials in both commercial and industrial piping applications [6,10-12]. Often, such installations also include the hybrid joints using adhesive, mechanical (e.g., threaded joints), welded and other types of the joints (e.g., soldered). Various types of pipe constructions (with fabricated joints), such as drainage pipes or pipelines, require leakage testing (both water and air, and also others) prior to operation [6,11,13-15]. Yalçin et al. [13] pointed out the need to undertake the issues of the pipe tightness control, due to the leakage problem in such systems. An important and at the same time potentially sensitive area is the pipe joints, in this case presented in this paper by means of the bonding. 
Some publications also discussed the resistance of the polymer pipe materials to various factors $[8,10]$. One of the problems raised by Makris et al. [10] is the service life of the polyvinyl chloride (PVC) pipes and its determination, due to PVC sewer pipes being operated in a hostile environment. The authors [8] discussed the influence of the aging process of the adhesive sleeve joints on the selected mechanical properties of these joints. Based on the results of the strength tests, it was possible to assess the aqueous environments impact on the adhesive joints strength. It was observed that the longer the seasoning time of the adhesive joint samples was, the more negative effects on the adhesive joints (decreased strength regardless of the adhesive type or the material). Some publications have also addressed the problem of assessing the tightness of the pipes and the pipe joints using both water and air tests [6,7,13]. Jensen and Agnone [7] presented a leak detection method for metal or plastic piping systems and a variety of joint types. They also pointed out that pipe joints are usually tested by hydrostatic or pneumatic methods. Wang et al. [16] emphasized the importance of leak detection in pipelines, as leakage from pipelines had the potential to cause important environmental and economic problems. Wang et al. [16] also highlighted that hydraulic leak detection was cheaper and gave faster results compared to other leak detection methods. Wong et al. [6] also underlined that the leakage was undesirable in water distribution networks, as leaky pipes were financially costly and the ability to detect, pinpoint the location and quantify leaks could affect the quality of the services provided. Van Zyl and Malde [7] indicated the importance of the problem of the changes in the leakage areas under the influence of pressure. For this reason, it seems that the technology of performing pipe joints plays a significant role. The important factor of the technology is not only the type of method used to join the pipes joint but also, in the case of adhesive joints, the type and properties of the adhesive. However, the type of material (pipe material) to be joined also plays an important role. Thus, it can be seen that the presented topic is very broad and covers many issues that are the subject of current research.

This article attempts to show that the type of adhesive can affect the quality of the adhesive joints, taking into account the tightness of the joints. This is very important in the case of pipe joints, which was also emphasized, among others, by Wong et al. [6] and Wang et al. [16]. The aim of the research was to determine the tightness of the adhesive joints of pipes made of the polymeric materials (application of the nondestructive testing) and to determine the strength of these joints (use of destructive testing). Both of these types of tests also allow for the assessment of the correctness of this type of joints. The leakage tests carried out were modeled on the water test for various pipes (e.g., drainage pipes) and pipelines.

\section{Materials and Methods}

\subsection{Adherends}

The samples were made of two types of the polymer materials: a polyvinyl chloride (PVC) and a polypropylene (PP). Three polyvinyl chloride pipes (type: PVC-U, producer: NIibco, Łódź, Poland) and two polypropylene pipes (type: PP-R, producer: Prawtech, Wolbrom, Poland) were used to make the samples. The pipes were delivered in tubular form. The diameters and wall thicknesses resulted from the available commercial dimensions of the pipes used in the water systems. The dimensions and the designations of the used pipes are given in Table 1.

Table 1. Dimension of polymer pipes.

\begin{tabular}{cccccc}
\hline Type of Material & \multicolumn{2}{c}{ Polyvinyl Chloride (PVC) } & \multicolumn{2}{c}{ Polypropylene (PP) } \\
\hline Diameter, mm & 26.5 & 21.1 & 15.5 & 25.0 & 20.0 \\
Thickness of wall, mm & 2.2 & 1.8 & 1.8 & 4.5 & 3.5 \\
Designation & PVC-26.5 & PVC-21.1 & PVC-15.5 & PP-25 & PP-20 \\
\hline
\end{tabular}

Polyvinyl chloride (PVC) is a synthetic polymer from the group of vinyl polymers. It is thermoplastic and has high mechanical strength. Figure 1a shows the structural model 
of PVC. Polypropylene (PP) is a hydrocarbon thermoplastic polymer from polyolefins, obtained by low-pressure polymerization of propylene. A structural model of PP is shown in Figure $1 b$.

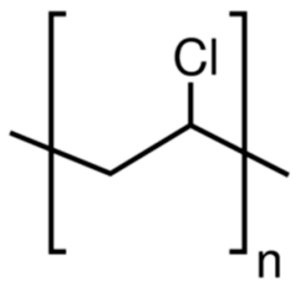

(a)

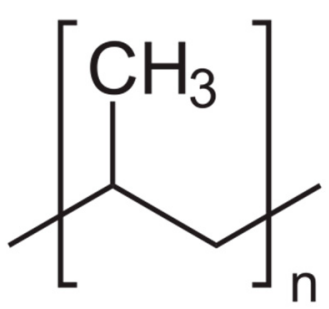

(b)

Figure 1. Structural model: (a) polyvinyl chloride [17]; (b) polypropylene [18].

The mechanical properties of the polymer materials are presented in Table 2.

Table 2. Mechanical properties of polymer pipes [19].

\begin{tabular}{ccc}
\hline \multirow{2}{*}{ Mechanical Properties } & \multicolumn{2}{c}{ Type of Material } \\
\cline { 2 - 3 } & Polyvinyl Chloride (PVC-U) & Polypropylene (PP-R) \\
\hline Young modulus ${ }^{1}$ & $2758 \mathrm{MPa}$ & $850-900 \mathrm{MPa}$ \\
Tensile strength & $48.3 \mathrm{MPa}$ & $27 \mathrm{MPa}$ \\
Stress in plastic deformation ${ }^{2}$ & & $32 \mathrm{MPa}$ \\
Stress at break $^{2}$ & & $10-14 \%$ \\
Elongation at break $^{2}$ & &
\end{tabular}

${ }^{1}$ ISO 527-1. ${ }^{2}$ ISO 527-1-2.

\subsection{Adhesives}

Two types of the adhesive were used to make the adhesive joints: Loctite $3430 \mathrm{~A} \& \mathrm{~B}$ Hysol (Henkel LOCTITE ${ }^{\circledR}$, Düsseldorf, Germany), two-component epoxy adhesive, and Loctite 406 (Henkel LOCTITE ${ }^{\circledR}$, Düsseldorf, Germany), one-component cyanoacrylate adhesive. Loctite 3430 A\&B Hysol is a two-component adhesive consisting of an epoxy resin and curing agent. The resin and the curing agent were mixed at a ratio of 1:1. The adhesive was then applied to the surface of one of the bonded components. The curing time at room temperature was about $2 \mathrm{~h}$. The epoxy adhesives have a good adhesion to the surface of many materials due to the presence of the polar hydroxide and ether groups.

As a single-component Loctite 406 cyanoacrylate adhesive, it does not require mixing and is contained in an easy-to-apply applicator package. The adhesive used cures when exposed to moisture in the air. The curing takes place after a few seconds, but the chemical resistance of the joint made of this adhesive is achieved after about $24 \mathrm{~h}$ [20].

\subsection{Adhesive Joints}

The butt-adhesive joints of the polymer pipes were used for testing the leak-tightness and the tensile strength. The diameter and wall thickness are shown in Table 1, and the bonding area is shown in Table 3. An example of the shape of the joint is shown in Figure 2.

Table 3. Dimension of adhesive bonding area.

\begin{tabular}{cccccc}
\hline Type of Material & \multicolumn{2}{c}{ Polyvinyl Chloride (PVC) } & \multicolumn{2}{c}{ Polypropylene (PP) } \\
\hline Designation of pipes & PVC-26.5 & PVC-21.1 & PVC-15.9 & PP-25 & PP-20 \\
Bonding area, mm $^{2}$ & 89.5 & 57.1 & 41.3 & 160.7 & 100.3 \\
\hline
\end{tabular}




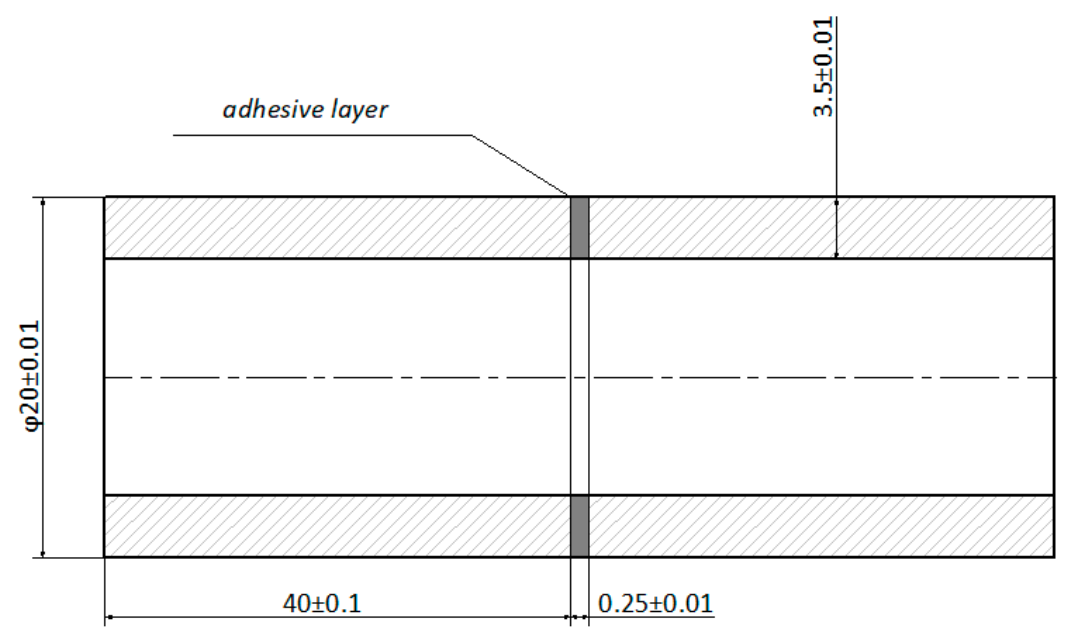

Figure 2. Scheme of adhesive joint of PP pipes with a diameter of $20 \mathrm{~mm}$ (PP-20) (dimensions in $\mathrm{mm}$ ).

The thickness of the adhesive layer (bond line) is an important element with a significant influence on the quality of the adhesive joints. The thickness of the adhesive layer was determined with an indirect method, using an electronic caliper with an accuracy of $0.01 \mathrm{~mm}$. The thickness of the adhesive joint (mean value) in the adhesive joints of PP pipes made with Loctite $3430 \mathrm{~A} \& \mathrm{~B}$ Hysol adhesive was $0.25 \pm 0.01 \mathrm{~mm}$, while in the case of Loctite 406 adhesive, it was $0.17 \pm 0.01 \mathrm{~mm}$. The thickness of the adhesive joint (mean value) in the adhesive joints of PVC pipes made with Loctite 3430 A\&B Hysol adhesive was $0.21 \pm 0.02 \mathrm{~mm}$, whereas in the case of Loctite 406 adhesive, it was $0.15 \pm 0.01 \mathrm{~mm}$. It can be seen that the pipes samples bonded with Loctite 3430 A\&B Hysol adhesive had a thicker adhesive layer than those bonded with Loctite 406, which may be due, among other things, to the lower viscosity of Loctite $406(15-25 \mathrm{mPa} \cdot \mathrm{s}$ [20]) than that of Loctite 3430 A\&B Hysol (18,000-28,000 $\mathrm{mPa} \cdot \mathrm{s}$ [21]).

Ten types (series) of such adhesive joints have been identified, depending on the type of the polymer material, the diameter of the pipes (and their wall thickness) (Table 1) and the type of the adhesive. Each series contained 6 adhesive joints; therefore, a total of 60 adhesive joints were made.

\subsection{Adhesive Joints Preparation}

The samples of polymer pipes for the bonding process were made in two stages. In the first stage, samples of appropriate dimensions were made by cutting. However, in the second stage, the surface of the samples was prepared strictly for the bonding process, before applying the adhesive, i.e., mechanical treatment and degreasing were applied.

In the first step, the samples of the polymer pipes were cut using a pipe cutter (Stanley, Praha, Czech Republic, cutting capacity up to $42 \mathrm{~mm}$ ). Then, pipe samples were subjected to face treatment using a high-speed steel tool on a special stand. The samples as sleeves were fixed with a pin, which ensured the alignment of the samples. After machining the end faces, the samples were obtained perpendicularly to the symmetry axis. Additional treatment was applied to the few samples for which burrs appeared with a Topex grinding machine model SF125 (Graphite, Hengshui, China) with two discs $125 \mathrm{~mm}$ in diameter and $16 \mathrm{~mm}$ thick and rotational speed of $2950 \mathrm{rpm}$.

In the second stage, the end faces of the pipes intended for bonding were mechanically treated and degreased. The mechanical treatment consisted of processing with P500 sandpaper, with circular movements for $30 \mathrm{~s}$. The next stage of the surface preparation process was degreasing the bonded surface from any contamination. This stage was performed after mechanical treatment in order to remove the impurities formed during this process. The surface was degreased by spraying the bonded surface with Loctite SF7061 acetone-based degreasing agent (Henkel LOCTITE ${ }^{\circledR}$, Düsseldorf, Germany). 
The bonding process was carried out at the temperature of $22 \pm 1^{\circ} \mathrm{C}$, while the humidity was $27 \pm 2 \%$. The bonding of the adherends was carried out after drying the degreasing agent using Loctite 3430 A\&B Hysol epoxy adhesive and Loctite 406 cyanoacrylate adhesive. In both cases, the same technique of applying the adhesive was used, on the surface of one of the adherend. Then, both adherends were fixed, and pressure $(0.018 \mathrm{MPa})$ was exerted on them in a special fixing device for $72 \mathrm{~h}$. The curing was carried out for $72 \mathrm{~h}$ at $22 \pm 1{ }^{\circ} \mathrm{C}$, with $27 \pm 2 \%$ humidity.

\subsection{Leak-Tightness and Strength Tests}

The experimental tests consisted of determining the following tests: (i) the leaktightness of the polymer pipes adhesive butt joints (nondestructive tests) and (ii) the shear strength of these joints (destructive tests). Two stands were used to carry out the tests:

- A stand for testing the leak-tightness of the sample, using the appropriate test methodology [22],

- The Zwick/Roell Z150 testing machine with computer set and testXpert software, using DIN EN 1465 standard. The shear strength test was carried out in the ambient temperature. The test speed was $5 \mathrm{~mm} / \mathrm{min}$.

In addition, during the leak-tightness test, devices for visual assessment of the adhesive joints were used, such as Peak No. 1996 L magnifying glass. A description of the test rig and the method of performing the leak-tightness test are given in Reference [22]. The test stand for the leak-tightness testing is shown in Figure 3.

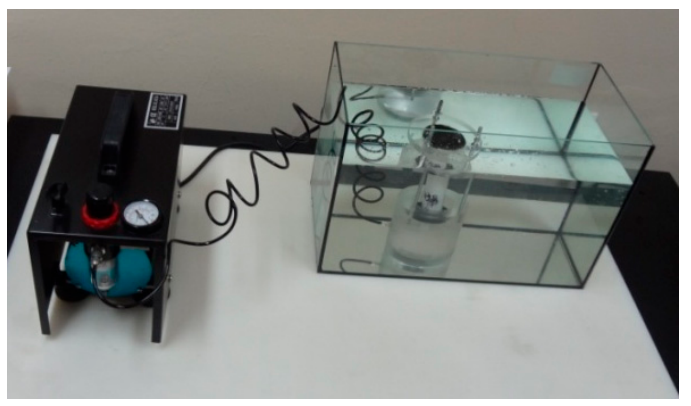

Figure 3. Test stand for leak-tightness testing.

The stand for the leak-tightness testing of the butt-adhesive joints consists of a holder for butt-adhesive sleeve specimens, which includes a hole for the joints to the compressor. This handle is located in a glass tank filled with a transparent liquid-water. The stand also includes a compressor that generates compressed air and delivers it to the sample holder and the tank. The adhesive joints sample was clamped in a holding fixture, which was placed in a container of water together with the clamped sample. The leak-tightness test was carried out at 4 bars, and the measuring time was $30 \mathrm{~s}$. By visually assessing the leaktightness of the butt-adhesive joints, it was possible to observe any drop in pressure and air bubbles escaping from the sample through the adhesive layer if the sample was leaking. After the tightness test, strength tests were carried out for all the adhesive joints made.

After the leak-tightness test, the adhesive joint specimens were clamped in the grips of the testing machine using a special grip (Figure 4) and then subjected to tensile loading until the joint failed. Prior to the strength test, the specimens had to be prepared to be placed in the grips of the testing machine. To this end, the transverse holes were drilled in both sides of the specimen to accommodate the pins used to secure the specimen to the machine. The holes were drilled using a Gude GTB 16/5A stationary drill with a $5 \mathrm{~mm}$ diameter drill. 


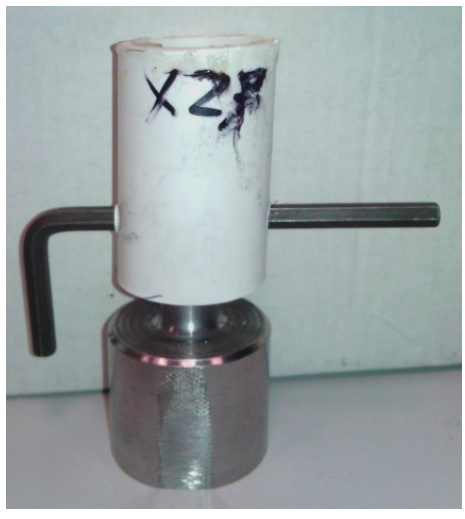

(a)

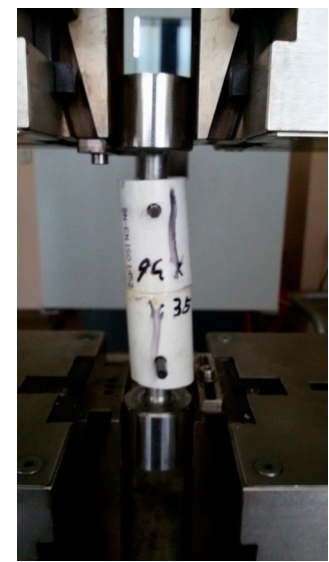

(b)

Figure 4. View of: (a) sample holder, for example, mounted on damaged sample; (b) adhesive joints sample with holder is mounted in jaws of testing machine.

\section{Results}

\subsection{Leak-Tightness Test}

Table 4 shows a comparison of the leak-tightness test results for the adhesive joints samples bonded with Loctite 3430 A\&B Hysol and Loctite 406.

Table 4. Number of leaks found in samples of butt-adhesive joints tested for leak-tightness.

\begin{tabular}{|c|c|c|c|c|}
\hline \multirow[t]{2}{*}{ Designation of Pipe } & \multicolumn{2}{|c|}{ Loctite 3430 A\&B Hysol } & \multicolumn{2}{|c|}{ Loctite 406} \\
\hline & Number of Leaky Samples & Number of Leaks & Number of Leaky Samples & Number of Leaks \\
\hline \multicolumn{5}{|l|}{ Polyvinyl chloride (PVC) } \\
\hline PVC- 26.5 & 0 & 0 & 2 & $1 / 1^{1} ; 2 / 2^{1}$ \\
\hline PVC-21.1 & 0 & 0 & 1 & $1 / 1^{1}$ \\
\hline PVC-15.9 & 4 & $\begin{array}{c}1 / 2^{1} ; 2 / 2^{1} ; 3 / 1^{1} \\
4 / 1^{1}\end{array}$ & 0 & 0 \\
\hline \multicolumn{5}{|l|}{ Polypropylene (PP) } \\
\hline PP-25 & 0 & 0 & 1 & $1 / 2^{1}$ \\
\hline PP-20 & 2 & $1 / 1^{1} ; 2 / 1^{1}$ & 0 & 0 \\
\hline
\end{tabular}

${ }^{1}$ Number of leaks per sample.

No leaks were detected among the samples of the adhesive joints made of PVC with a diameter of $26.5 \mathrm{~mm}$ and a wall thickness of $2.2 \mathrm{~mm}$ (PVC-26.5, Figure 5a). The same was for the adhesive joints made of PVC with a diameter of $21.1 \mathrm{~mm}$ and a wall thickness of $1.8 \mathrm{~mm}$ (PVC-21.1) bonded with Loctite 3430 A\&B Hysol adhesive.

Among the adhesive joint samples made of $15.5 \mathrm{~mm}$ diameter PVC with a wall thickness of $1.8 \mathrm{~mm}$ (PVC-15.9) bonded with Loctite 3430 A\&B Hysol adhesive, four leaky samples were found, but only two were leak-proof. One of sample had two leaks visible under the magnifying glass, the second sample also had two leaks, but they were not visible under the magnifying glass, and the air outflow from them was slow. Two consecutive samples had one leak each.

Among the samples of the adhesive joints from PP pipe with a diameter of $25 \mathrm{~mm}$ and a wall thickness of $4.5 \mathrm{~mm}$ (PP-25) bonded with Loctite 3430 A\&B Hysol adhesive, all were tight. Among the samples of the adhesive joints made of PP pipe with a diameter of $20 \mathrm{~mm}$ and a wall thickness of $3.5 \mathrm{~mm}$ (PP-20) prepared with Loctite 3430 A\&B Hysol adhesive, four samples were found to be leak-proof, while two were found to be leaky. The leaks in the leaky samples were visible under a magnifying glass, and each of these samples had one leak. 


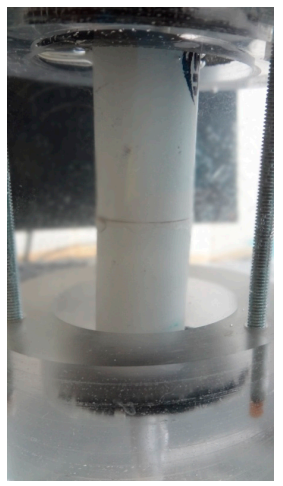

(a)

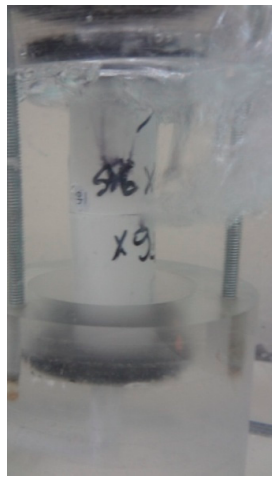

(b)

Figure 5. View of sample of adhesive joint (PVC-26.5): (a) leak-proof sample made by Loctite 3430 A\&B Hysol adhesive; (b) leaky sample made by Loctite 406.

Among the adhesive joint samples of $26.5 \mathrm{~mm}$ diameter PVC pipes with a wall thickness of $2.2 \mathrm{~mm}$ (PVC-26.5) prepared with Loctite 406 adhesive, three leaks and two leaky samples were observed (Figure $5 b$ ). In one sample, one leak was visible through the magnifying glass, while the other was not visible through the magnifying glass and had a small amount of air coming out of it. The second sample had one leak visible through the magnifying glass. Among the adhesive joint samples of $21.1 \mathrm{~mm}$ diameter PVC pipes with a wall thickness of $1.8 \mathrm{~mm}$ (PVC-21.1) bonded with Loctite 406 adhesive, five samples were tight, while one sample was found to be leaking. In addition, this sample had one leak visible through a magnifying glass. No leaks were detected among samples of the adhesive joints of the PVC pipes with a diameter of $15.5 \mathrm{~mm}$ and a wall thickness of $1.8 \mathrm{~mm}$ (PVC-15.9) bonded with Loctite 406 cyanoacrylate adhesive.

Among the samples of the adhesive joints of PP pipes with a diameter of $25 \mathrm{~mm}$ and a wall thickness of $4.5 \mathrm{~mm}$ (PP-25) prepared with Loctite 406 adhesive, one leaky sample was detected. The leaky sample contained two leaks, visible under the magnifying glass, whereas no leaks were detected among the samples of the adhesive joints of PP pipes with a diameter of $20 \mathrm{~mm}$ and a wall thickness of $3.5 \mathrm{~mm}$ (PP-20) bonded with Loctite 406 adhesive.

Figure 6a shows the adhesive joint of PP pipe with a diameter of $25 \mathrm{~mm}$ and a wall thickness of $4.5 \mathrm{~mm}$ bonded with Loctite 3430 A\&B Hysol adhesive, which showed a leaktightness joint. In the leaky sample of the adhesive joints of PP pipes with a diameter of $25 \mathrm{~mm}$ and a wall thickness of $4.5 \mathrm{~mm}$ (PP-25) bonded with Loctite 406 adhesive (Figure 6b), there were two leaks, visible during the leak-tightness test and when checked visually using a Peak No. 1996 L magnifier.

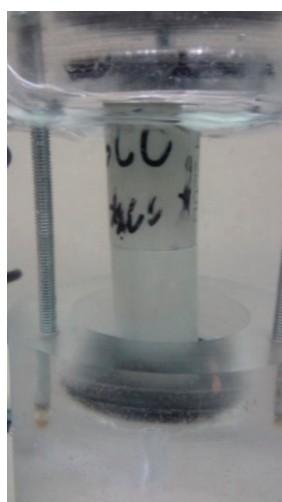

(a)

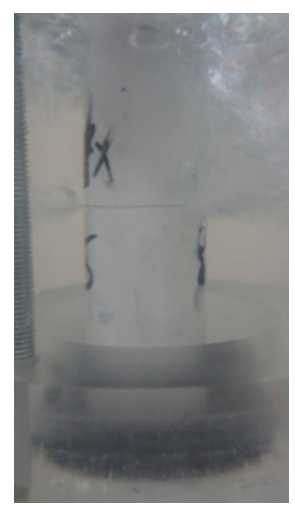

(b)

Figure 6. View of sample of adhesive joint (PP-25): (a) leak-proof sample made by Loctite $3430 \mathrm{~A} \& \mathrm{~B}$ Hysol adhesive; (b) leaky sample made by Loctite 406. 


\subsection{Strenght Test}

\subsubsection{Tensile Strength}

Figure 7 shows a comparison of the tensile strength of the butt-adhesive joints samples made with Loctite 3430 A\&B Hysol adhesive and Loctite 406 adhesive.

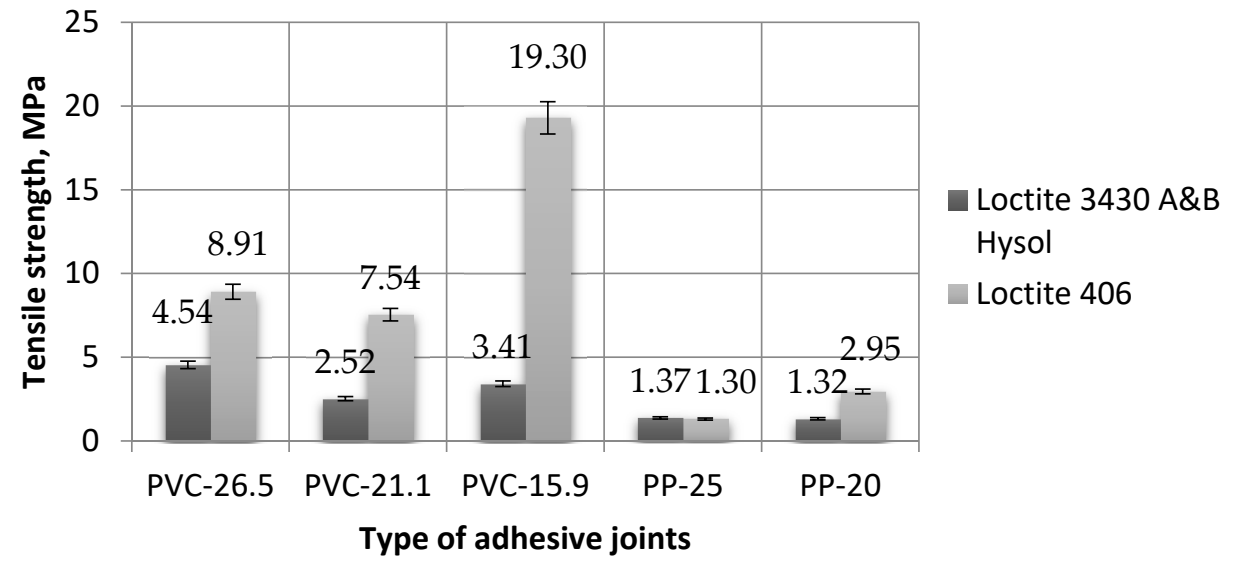

Figure 7. Tensile strength of butt-adhesive joints samples made with Loctite 3430 A\&B Hysol adhesive and Loctite 406 adhesive.

Comparing the strength results of the joints made with Loctite 3430 A\&B Hysol adhesive (Figure 7), it can be observed that despite the larger adhesive surface area, PP pipe adhesive joint samples achieved a lower strength than PVC pipe adhesive joint samples. PVC pipe adhesive joint samples with a diameter of $26.5 \mathrm{~mm}$ and a wall thickness of $2.2 \mathrm{~mm}$ were five times stronger than PP pipe adhesive joint samples, which had a thicker wall and a larger the bonded area (PP-25). It is worth noting that among PVC pipe adhesive joints, the strength was related to the size of the bonded area: the smaller the bonded area, the lower the strength. The samples of the adhesive joints of the pipes from PVC-21.1 and PVC-15.5, despite the same size of bonded area, had different tensile strengths. The samples of the adhesive joints of PVC-15.9 pipes showed higher strength than the samples of adhesive joints of PVC-21.1 pipes. It can be concluded that the use of Loctite $3430 \mathrm{~A} \& \mathrm{~B}$ Hysol is preferable for bonding PVC pipes.

The data presented in Figure 7, concerning the strength of adhesive joints made with Loctite 406 adhesive, show that the adhesive joints of PP pipes are characterized by lower strength than the adhesive joints of PVC pipes, despite the larger bonding areas. The adhesive joints of PVC pipes with a diameter of $15.9 \mathrm{~mm}$ and a wall thickness of $1.8 \mathrm{~mm}$ had the highest strength (PVC-15.5). They were about twice as strong as other PVC pipe adhesive joints and about eight times as strong as PP pipe adhesive joints. In the case of Loctite 406 adhesive, the size of the bonding area had little effect on the tensile strength.

\subsubsection{Elongation at Break}

Figure 8 shows the values of elongation at break of the polymer pipe adhesive joint samples (mean values) made with Loctite 3430 A\&B Hysol adhesive and Loctite 406 adhesive. The examples of the force-strain curves for the adhesive joints of PP pipes (PP-25) made with Loctite 3430 A\&B Hysol adhesive and Loctite 406 adhesive were presented in Figure 9. 


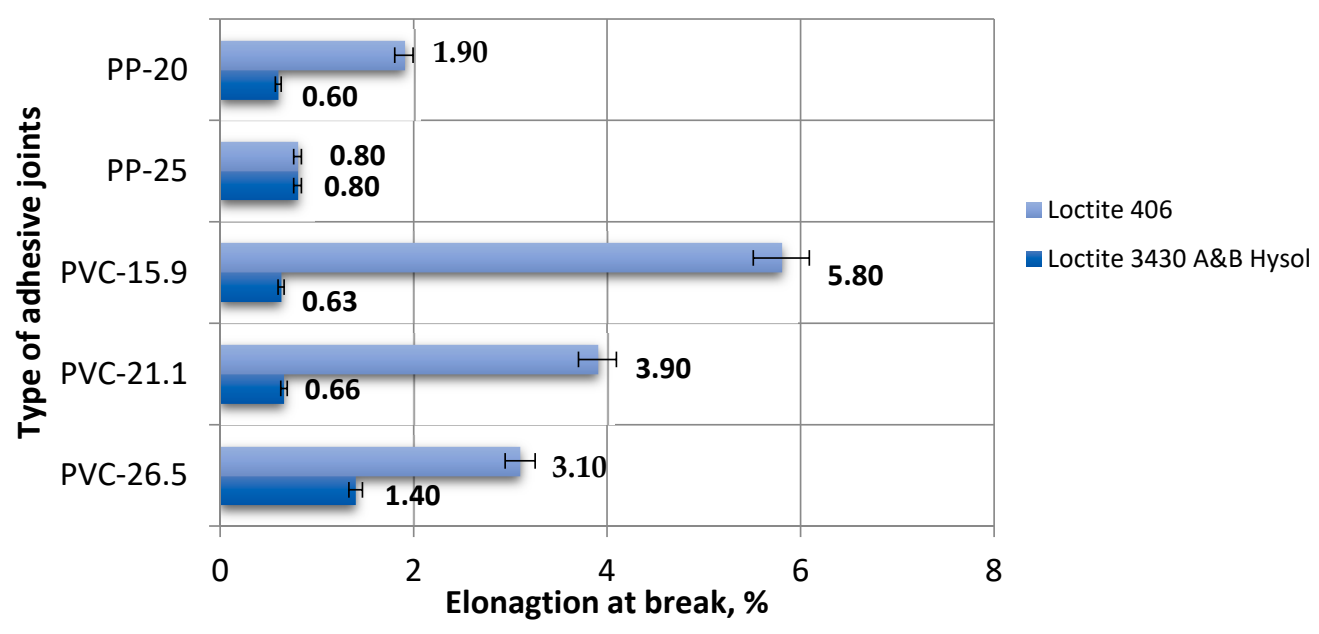

Figure 8. Elongation and break of butt-adhesive joints samples made with Loctite 3430 A\&B Hysol adhesive and Loctite 406 adhesive.

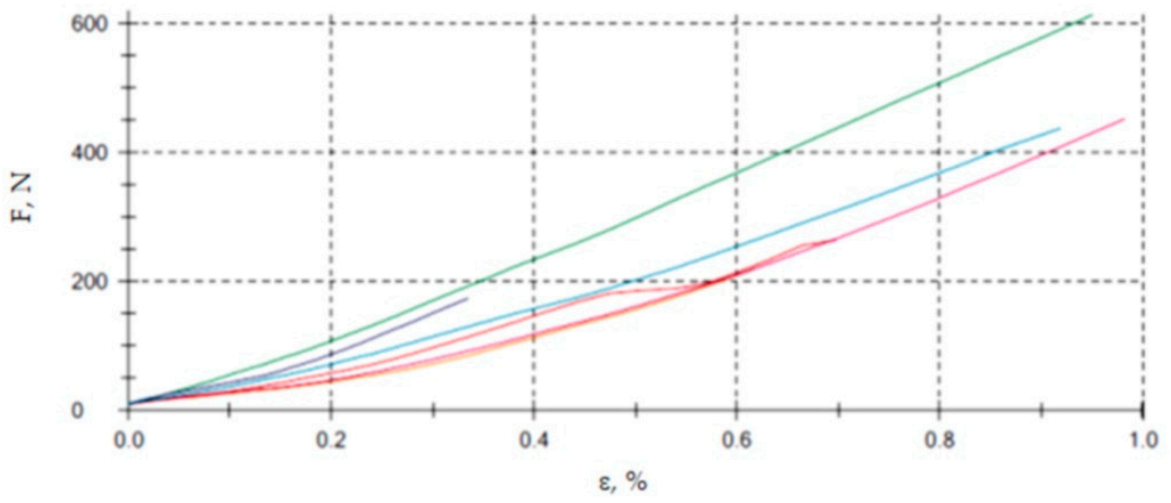

(a)

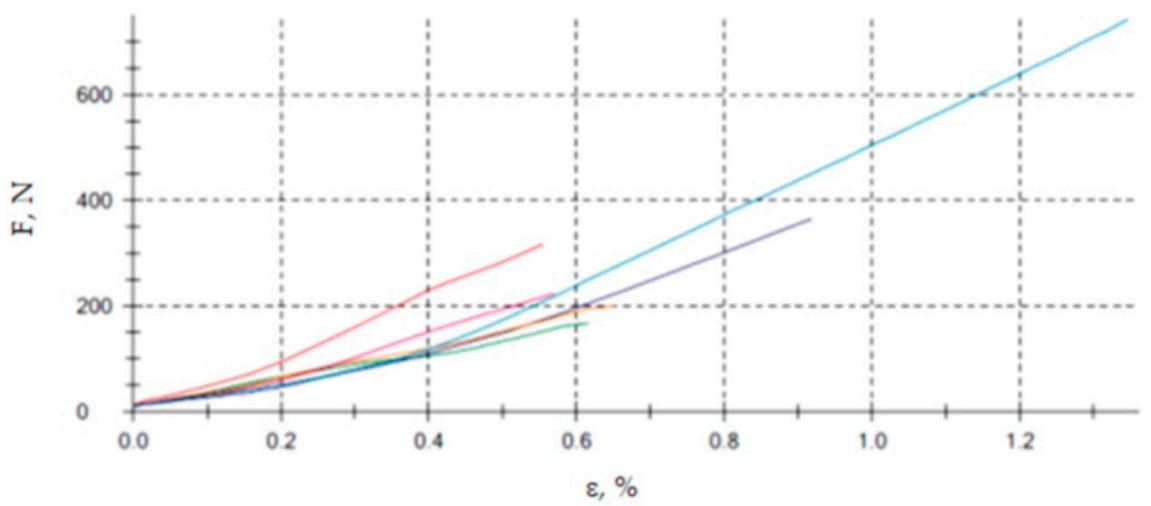

(b)

Figure 9. Force-strain curves of the adhesive joints of the polypropylene pipes (PP-25) made with: (a) Loctite 3430 A\&B Hysol adhesive and (b) Loctite 406 adhesive: F-force, $\varepsilon$-strain.

Examining the elongation at break of the adhesive joints of the polymer pipes made with Loctite 3430 A\&B Hysol adhesive (Figures 8 and 9a), it was observed that the elongation at break of the samples of PVC pipes adhesive joints was slightly higher than that of the adhesive joints of PP pipes (comparing individual sizes of similar pipe diameters, i.e., PVC-26.6 and PP-25, and PVC-21.1 and PP-20). The highest elongation at break was 
observed in the adhesive joints of PVC pipes with a diameter of $26.5 \mathrm{~mm}$ and wall thickness of $2.2 \mathrm{~mm}$ (PVC-26.5), which amounted to $1.4 \mathrm{~mm}$. The remaining adhesive joints of PVC pipes (PVC-21.1 and PVC15.5) were characterized by twice as low values of the elongation at break. In both types of the polymer pipes, the adhesive joints with larger diameters, i.e., with a higher value of the bonding area, exhibited higher elongations.

Considering the results of the adhesive joints of the polymer pipes made with Loctite 406 adhesive (Figures 8 and 9 b), it was noted that:

- The samples of the PVC pipes adhesive joints have higher elongation at break values than those of PP pipes adhesive joints;

- With the decrease in pipe diameter (and also with the decrease in the bonding area size-Table 3), the elongation at break value increases, and this relation applies to both types of the polymer pipe materials (both PVC pipes and PP pipes), which is the opposite relation observed in the case of the adhesive joints of these pipes but made with the Loctite 3430 A\&B Hysol adhesive;

- In particular types of the polymer pipes adhesive joints, the elongation at break of the joints between maximum and minimum elongation values is twice as high (PP-25 and PP-20 as well as PVC-26.5 and PVC-15.9).

\section{Discussion}

\subsection{Leak-Tightness Test Results}

Based on the leak-tightness test results, it can be concluded that the adhesives used for the butt-adhesive joints have similar leak-tightness characteristics. The leak-tightness occurred in two series of the adhesive joint samples bonded with Loctite 3430 A\&B Hysol adhesive, and three series of the adhesive joints samples bonded with Loctite 406 adhesive. It should be noted that the majority of leak-tightness in the samples bonded with epoxy adhesive consisted of a series of the samples from $\varphi 15.9 \mathrm{~mm}$ PVC pipes (PVC-15.9), which could be due to defects occurring during the bonding process. It can also be noted that the diameter of the polymer pipes had no effect on the occurrence of the adhesive joint leak-tightness during the tests. Figures 5 and 6 show the examples of the adhesive joints samples that were with leak-tightness and with leak. The main cause of the leaks could be errors during the bonding process, appearing mainly at the stage of fixing and curing the adhesive joints. Although care has been taken to exercise extreme care when making the adhesive joints, the influence of the interfering factors may arise. The type of the adhesive for which the curing time differs is also an important factor. The errors in making the adhesive joints were rather not related to the errors in making pipe samples during the cutting process. This is because the perpendicularity of the pipe axis in relation to the face surface was maintained, which was checked after cutting the pipes, using the appropriate equipment. The technology of making the samples of pipes for bonding is described in Reference [8].

\subsection{Strength Test Results}

Summarizing the overall results presented in Figure 7, it was observed that the adhesive joints of the polymer pipes made with Loctite 406 adhesive showed a higher tensile strength than pipe adhesive joints bonded with Loctite 3430 A\&B Hysol. Only in the sample of PP pipe adhesive joints with a diameter of $25 \mathrm{~mm}$ (PP-25) were the strength values of the two adhesives similar. In other samples, the strength of adhesive joints bonded with Loctite 3430 A\&B Hysol adhesive was 40\% (PP-20), 60\% (PVC-26.5), 52\% (PVC-21.1) and $85 \%$ (PVC-15.9) of the strength of the adhesive joints of the same joints, respectively, but made with Loctite 406 adhesive. In the samples of the adhesive joints of the pipes from PVC of the diameter of $15.5 \mathrm{~mm}$ (PVC-15.5), the difference between the adhesives was large, and it could have resulted, among others, from defects of the samples of the adhesive joints made with Loctite 3430 A\&B Hysol adhesive, occurring during the bonding process, and detected during leak-tightness tests. The epoxy adhesive (Loctite $3430 \mathrm{~A} \& \mathrm{~B}$ Hysol) reaches its high strength at room temperature after approximately $2 \mathrm{~h}$. Compared to other epoxy 
adhesives, this is an advantageous property, as epoxy adhesives usually achieve adequate strength after a much longer curing time. The relatively short curing time favors the use of such adhesive in production works related to the performance of the adhesive joints. In the case of a cyanoacrylate adhesive (Loctite 406), it is used when a quick installation is required. Although the functional strength is obtained by the adhesive in a relatively short time, the manufacturer mentions that the full strength of the adhesive joints is achieved after $24 \mathrm{~h}$. Therefore, in terms of the curing time, both used adhesives are comparable.

According to the manufacturer's data [20,21], the shear strength of the adhesive joints made with $\mathrm{A} \& \mathrm{~B}$ Hysol adhesive and cured for $16 \mathrm{~h}$ at $40{ }^{\circ} \mathrm{C}$ allows for the following results: for polycarbonate joints, the strength is $5 \mathrm{MPa}$, and for $\mathrm{ABS}$ polymer joints- $3 \mathrm{MPa}$. In turn, for adhesive joints made with the cyanoacrylate adhesive, the shear strength (curing time: $24 \mathrm{~h}$ and temperature $22^{\circ} \mathrm{C}$ ) for polycarbonate joints is $9.1 \mathrm{MPa}$, for ABS polymer- $8.8 \mathrm{MPa}$, and for PVC joints-8.7 MPa. Although the presented data of the manufacturer concerns the shear strength (according to a specific standard) of the adhesive joints with a specific geometry, made under certain conditions, it can be noticed that the adhesive joints made with the cyanoacrylate adhesive show greater strength. In the experiment, a different type of adhesive joints was made-butt joints, where there was also a different direction of the force. However, it has been shown that the type of the adhesive plays a significant role in the fabrication of the adhesive joints, irrespective of the type of load acting on the joint.

Taking into account the material of the polymer pipes from which the adhesive joints were made and analyzing the correlation coefficient (the Pearson linear correlation coefficient $r$ ) between the size of the bonding area and the elongation at break of the polymer pipes adhesive joints, it was observed that:

- In the case of adhesive joints made with Loctite 3430 A\&B Hysol, both of PVC and PP pipes, a strong correlation was obtained between the size of the bonding area and the elongation at break value. In the case of PVC pipe adhesive joints, the correlation coefficient is 0.96 , and in the case of the polypropylene pipe adhesive joints, the correlation coefficient is 1.00 . The added sign of the coefficient means that as the bonding area increases, the elongation at break value increases, and this applies to the adhesive joints of both types of the polymer pipes;

- When considering the correlation between the size of the bonding area and the elongation at break of the adhesive joints of the polymer pipes made with Loctite 406, the correlation coefficient was -0.91 (the adhesive joints of PVC pipes) and -1 (the adhesive joints of PP pipes). This means that there is a strong correlation between the size of the bonding area and the elongation at break of the adhesive joints, with the elongation decreasing as the bonding area increases.

- It may result from both the cohesive properties of the adhesive and the adhesive properties at the interface between the surface of the joined elements and the adhesive. The adhesives used differ in both the chemical base and the viscosity. The abovementioned factors may result in obtaining various dependencies related to the elongation of the considered adhesive joints.

On this basis, it can be concluded that the type of the adhesive has a significant effect on the strength results and is important when designing adhesive joints. Due to the adhesion forces in the adhesive joints, the adhesive layers that are directly adjacent to the adherends cannot undergo normal deformation in the plane of the adhesive joint (radial). The other layers of the adhesive joint undergo such deformation under the load of the joint with forces normal to the bonded surfaces (axial). The walls of adhesive layer are subject to deformation and a constriction occurs in such an adhesive joint [1]; however, this depends, among others, on the mechanical properties of the adhesive in the cured state. Habenicht [2] emphasized that adhesive joints require an appropriate size of the bonding surface, because the adhesive layer (in the case of adhesive joints subjected to tensile stress) is a weak link in the construction of such joints. In the presented research, a strong correlation was found between the bonding area and the elongation at break. However, on the other hand, these dependencies do not apply to all adhesive joints of the 
polymers, especially when the adhesives and the adherends have comparable strength. For example, in the analyzed case, the E modulus of Loctite 3430 A\&B Hysol adhesive is $2500 \mathrm{MPa}$ [21], while the E modulus for PP is 1500-2000 MPa and for PVC from 2400 to $4000 \mathrm{MPa}$. For this reason, in the analyzed cases, the type of adhesive has a significant impact on the strength results, and it is extremely important when designing this type of joints.

Some issues concerning the dependence of the geometrical dimensions of the adhesive joints, including the thickness of the adhesive joint, are presented in the works by Taib et al. [3], Liao et al. [4], da Silva et al. [5], Davies et al. [23], and Rudawska [24]. These references underlined that the decreased failure load to increasing bond thickness in terms of the stress state (i.e., plane stress or plane strain) prevailing inside the adhesive layer. Liao et al. [4] demonstrated that in the case of the adhesive joints prepared with the ductile adhesive, the ultimate tensile loading increases as the adhesive layer thickness decreases. Although in this paper the bonding area was considered, it is also one of the geometrical factors of the adhesive joints, also related to the thickness of the adhesive layer.

A visual assessment of the failure of the pipe adhesive joints was made, using the EN ISO 10365 standard. Based on the test results, it can be assessed that in all cases of the adhesive joints, the failure is concerned with adhesive type failure (according to EN ISO 10365), and no failure was noticed of cohesive failure in the pipes-the joined material. When visually assessing the type of the adhesive failure, it was noticed that:

- For the adhesive joints of pipes made with two-component epoxy adhesive, there were the following two types of failure: a special cohesion failure (SCF) $-34 \%$ of all evaluated pipe adhesive joints-and an adhesion failure (AF) - $66 \%$ of all evaluated pipe adhesive joints;

- For the adhesive joints of pipes made with one-component cyanoacrylate adhesive, for almost all of the assessed adhesive joints, the adhesive failure type (AF) was noted.

It can therefore be assumed that the type of the adhesive used to make the joints also plays an important role.

It can be assumed that the obtained results of mechanical properties and noticed relations were influenced both by the type of adhesive and the technology of making the adhesive joints (depending also on the properties of the adhesive, among others, on its viscosity).

\section{Conclusions}

After analyzing the results of the performed experimental tests, the following conclusions can be formulated:

- The sealing properties of Loctite 3430 A\&B Hysol and Loctite 406 adhesives are similar, and the main factor in obtaining a leak-proof sample is the correct course of the bonding process, in particular the stages of pressing, fixing the joined elements and curing the adhesive;

- The geometrical accuracy of the adherends has a great influence on the tightness and the strength of the adhesive joints,

- The adhesive joints made with Loctite 406 cyanoacrylate adhesive have higher the strength than the adhesive joints made with Loctite 3430 A\&B Hysol two-component epoxy adhesive;

- The type of the adhesive has a significant effect on the elongation at break of the adhesive joints.

It can be concluded that both the nondestructive and the destructive tests allowed one to determine the properties of the adhesive joints of the polymeric pipes. Thanks to leak-tightness tests, it was possible to determine the quality of their execution without destroying the samples, while thanks to the strength tests, their resistance to the tensile stresses was determined. Based on the test results, it has been shown that the type of the adhesive affects the quality of the adhesive joints in terms of both the tightness and 
the adhesive joints strength. This is especially important in relation to the use of such pipes in pipelines, and this knowledge can be helpful when designing these types of the pipe joints. The tests made it possible to conclude that with the analyzed types of the polymer pipe materials, in the case of the butt-adhesive joints, it is recommended to use the one-component cyanoacrylate adhesive.

It can be assumed that the obtained results of mechanical properties and noticed relations were influenced both by the type of adhesive and the technology of making the adhesive joints (depending also on the properties of the adhesive, among others, on its viscosity).

Author Contributions: Conceptualization, A.R.; methodology, A.R., M.A.W., M.M. and D.S.; software, A.R.; validation, A.R. and M.A.W.; formal analysis, A.R.; investigation, A.R., M.M. and D.S.; resources, A.R., M.M. and D.S.; data curation, A.R.; writing — original draft preparation, A.R.; writingreview and editing, A.R.; visualization, A.R., M.A.W., M.M. and D.S.; supervision, A.R., M.A.W. and D.S.; project administration, A.R.; funding acquisition, A.R. All authors have read and agreed to the published version of the manuscript.

Funding: Lublin University of Technology Grant Number: FD-20/IM-5/093. Recipient: Anna Rudawska.

Institutional Review Board Statement: Not applicable.

Informed Consent Statement: Not applicable.

Data Availability Statement: Data sharing not applicable.

Acknowledgments: Faculty of Mechanical Engineering, Lublin University of Technology, Lublin, Poland.

Conflicts of Interest: The author declares no conflict of interest.

\section{References}

1. Adams, R.D.; Comyn, J.; Wake, W.C. Structural Adhesive Joints in Engineering, 2nd ed.; Chapmann \& Hall: London, UK, 1997; pp. 140-144.

2. Habenicht, G. Applied Adhesive Bonding; Wiley-VCH Verlag GmbH \& Co. KGaA: Weinheim, Germany, 2006 ; pp. 139-143.

3. Taib, A.A.; Boukhili, R.; Achiou, S.; Gordon, S.; Boukehili, H. Bonded joints with composite adherends. Part I. Effect of specimen configuration, adhesive thickness, spew fillet and adherend stiffness on fracture. Int. J. Adhes. Adhes. 2006, 26, 226-236. [CrossRef]

4. Liao, L.; Huang, C.; Sawa, T. Effect of adhesive thickness, adhesive type and scarf angle on the mechanical properties of scarf adhesive joints. Int. J. Solids Struct. 2013, 50, 4333-4340. [CrossRef]

5. Da Silva, L.F.; Carbas, R.; Critchlow, G.W.; Figueiredo, M.; Brown, K. Effect of material, geometry, surface treatment and environment on the shear strength of single lap joints. Int. J. Adhes. Adhes. 2009, 29, 621-632. [CrossRef]

6. Wong, L.; Deo, R.; Rathnayaka, S.; Shannon, B.; Zhang, C.; Chiu, W.K.; Kodikara, J.; Widyastuti, H. Leak detection in water pipes using submersible optical optic-based pressure sensor. Sensors 2018, 18, 4192. [CrossRef] [PubMed]

7. Jensen, R.A.; Agnone, A.M. A new method to leak test piping joints. J. Manuf. Sci. Eng. 1996, 118, 604-609. [CrossRef]

8. Rudawska, A.; Wahab, M.A.; Müller, M. Effect of ageing process on mechanical properties of adhesive tubular butt joints in aqueous environment. Int. J. Adhes. Adhes. 2020, 96, 102466. [CrossRef]

9. Van Zyl, J.E.; Malde, R. Evaluating the pressure-leakage behaviour of leaks in water pipes. J. Wat. Supp. Res. Technol. AQUA 2017, 66, 287-299. [CrossRef]

10. Makris, K.F.; Langeveld, J.; Clemens, F.H.L.R. A review on the durability of PVC sewer pipes: Research vs. practice. Struct. Infrastruct. Eng. 2020, 16, 880-897. [CrossRef]

11. Marmarokopos, K.; Doukakis, D.; Frantziskonis, G.; Avlonitis, M. Leak detection in plastic water supply pipes with a high signal-to-noise ratio accelerometer. Measur. Contr. 2018, 51, 27-31. [CrossRef]

12. Sadr-Al-Sadati, S.A.; Jalili Ghazizadeh, M. Experimental study of crack behavior in pressurized high-density polyethylene water pipes. MethodsX 2019, 6, 1009-1020. [CrossRef] [PubMed]

13. Yalçin, B.C.; Torun, Z.; Balcilar, M.; Koyun, A. Design and servo control of a leak tightness working based on hydrostatic pressure aging method. Proc. Inst. Mech. Eng. Part I J. Sys. Cont. Eng. 2016, 230, 932-942. [CrossRef]

14. Liu, J.; Liu, G.; Wang, J.; Liu, S. Research on pipeline leakage identification method based on Lyapunov exponent spectrum. Vibroeng. Procedia 2019, 23, 61-65. [CrossRef]

15. ASTM F2164-21. Standard Practice for Filed Leak Testing of Polyethylene (PE) and Crosslinked Polyethylene (PEX) Pressure Piping Systems Using Hydrostatic Pressure. Available online: https://www.astm.org/f2164-21.html (accessed on 28 September 2021).

16. Wang, X.J.; Simpson, A.R.; Lambert, M.F.; Vítkovský, J.P. Leak detection in pipeline systems using hydraulic methods: A review. In Proceedings of the Conference on Hydraulics in Civil Engineering, the Institution of Engineers, Hobart, Australia, 23-30 November 2001; pp. 391-400. 
17. Polyvinyl Chloride. Available online: https://www.sigmaaldrich.com/PL/pl/product/aldrich/346764 (accessed on 28 September 2021).

18. Polypropylene. Available online: https:/ / en.wikipedia.org/wiki/Polypropylene (accessed on 28 September 2021).

19. Mechanical Properties of Polymer Pipes. Available online: http://www.instsani.pl/614/rury-z-polichlorku-winylu-pvc (accessed on 28 September 2021).

20. Loctite 406. Data Sheet. Available online: https://www.henkel-adhesives.com/pl/pl/produkty/instant-adhesives/loctite_406.html (accessed on 20 March 2021).

21. Loctite 3430 A\&B Hysol. Data Sheet. Available online: https://www.henkel-adhesives.com/pl/pl/produkty/structural-adhesives/ loctite_ea_3430.html (accessed on 20 March 2021).

22. Miturska, I.; Rudawska, A. Leakproofness control station of glue joints in the assembly processes. In Advanced Technologies in Designing, Engineering and Manufacturing. Research Problems; Jachowicz, T., Kłonica, M., Eds.; Perfekto Info: Lublin, Poland, 2015; pp. 88-100.

23. Davies, P.; Sohier, L.; Cognard, J.-Y.; Bourmaud, A.; Choqueuse, D.; Rinnert, E.; Créac'hcadec, R. Influence of adhesive bond line thickness on joint strength. Int. J. Adhes. Adhes. 2009, 29, 724-736. [CrossRef]

24. Rudawska, A. Influence of the thickness of joined elements on lap length of alluminium alloy sheet bonded joints. Adv. Sci. Technol. Res. J. 2015, 9, 35-44. [CrossRef] 